\title{
Effectiveness of Drought Tolerance Indices to Identify Tolerant Genotypes with High Yielding Potential in Tomato (Solanum lycopersicum L.)
}

\author{
Salvadora Buhroy ${ }^{1}$, T. Arumugam ${ }^{1}$, P. Irene Vethamoni ${ }^{1}$, \\ N. Manivannan ${ }^{2}$ and P. Jeyakumar ${ }^{3}$ \\ ${ }^{1}$ Department of Vegetable Crops, TNAU, Coimbatore-641003, Tamil Nadu, India \\ ${ }^{2}$ Department of Oilseeds, CPBG, TNAU, Coimbatore-641003, Tamil Nadu, India \\ ${ }^{3}$ Department of Crop Physiology, TNAU, Coimbatore-641003, Tamil Nadu, India \\ *Corresponding author
}

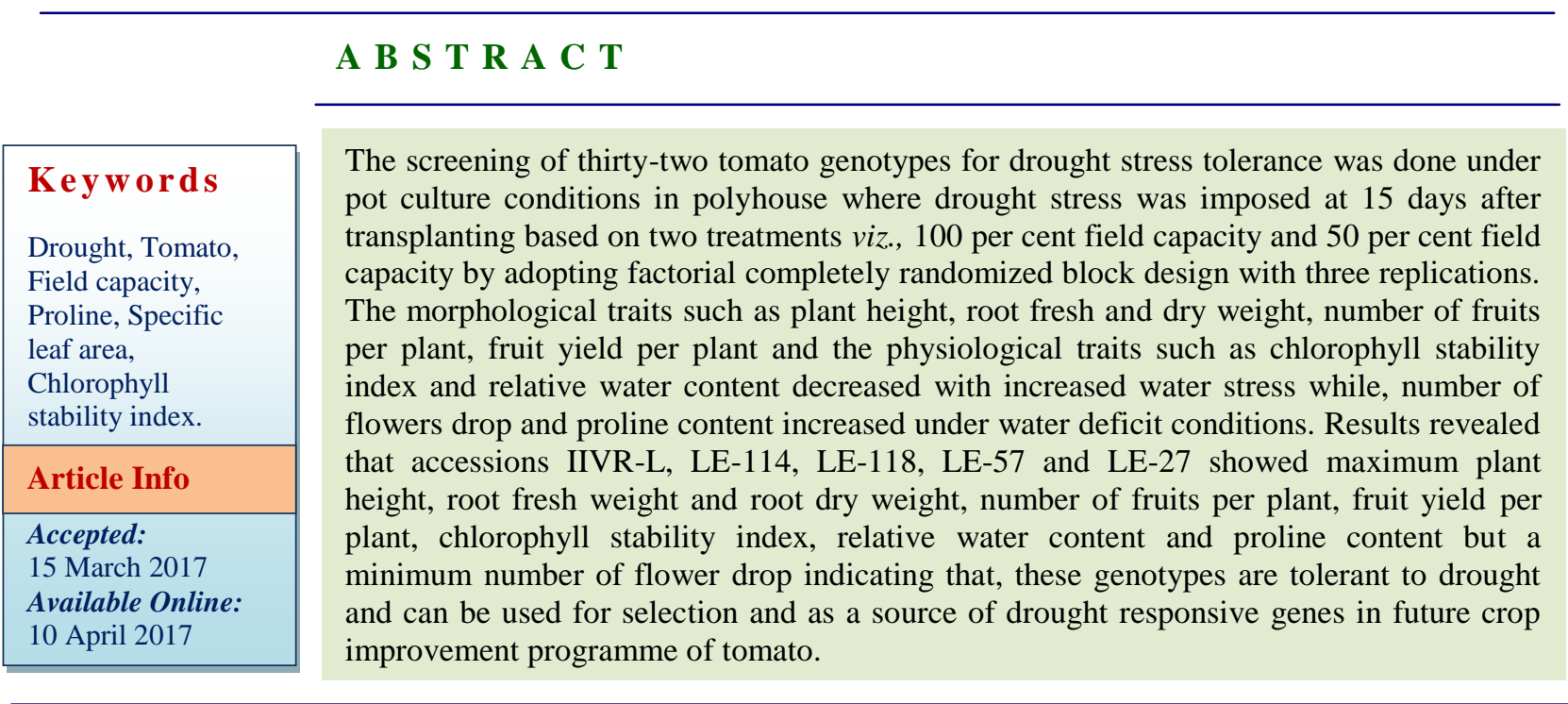

\section{Introduction}

The aggressive exploitation of natural resources has endangered water resources, biodiversity and soil quality and has threaten the increase of frequency and severity of extreme climatic events such as drought, excessive heat, floods and so on in the future. About two-third of the geographical area of India receives low rainfall i.e. less than 1000 $\mathrm{mm}$, which is also characterized by uneven and erratic distribution. The agriculture system in our country has been challenged with drought. Out of the net sown area of 140 million hectares, about $68 \%$ is reported to be vulnerable to drought stress and about $50 \%$ of such vulnerable area is classified as severe, where frequency of drought is almost regular (Chatterjee and Solankey, 2015).

Climate change is predicted to produce an increase in temperature and drought events in the next decades. Drought is by far the leading environmental stress in agriculture that limits global productivity of vegetable crops by directly reducing potential yield and also by indirectly influencing their interactions with biotic factors, as a 
consequence, playing a critical role on the world's food security (Foolad et al., 2003; Mir et al., 2012 and Mishra et al., 2016). Drought may be defined as a climatic hazard, implying the absence or very low level of rainfall for a week, month or years, long enough to cause moisture depletion in soil with a decline of water potential in plant tissues, reduction of stomatal conductance, metabolic processes and growth (Schachtman and Goodger, 2008).

Tomato (Solanum lycopersicum L.) having chromosome number $2 \mathrm{n}=24$ belongs to Solanaceae family and is one of the most popular, economically important vegetable crop grown worldwide. It is an excellent source of bioactive compounds such as vitamins, minerals and organic acids. Globally, it is treated as a protective food, as it is rich in dietary nutrients and anti-oxidants such as lycopene (anti-cancer properties) and other compounds such as chlorogenic acid, plastoquinones, rutin, tocopherol and xanthophylls (Agarwal and Rao, 2000 and Leonardi et al., 2000).

Besides its health benefits, the crop can serve as a source of income for farmers as a result of which it can reduce poverty because of its potential growth and employment creation (Anang et al., 2013). Thus, improving the livelihood of the farmers, however, the full potential of the crop has been under exploited because of any challenges by a number of biotic and abiotic factors.

Tomato is grown throughout the country under both rainfed and irrigated conditions. The critical period for watering in tomato is early flowering and fruit setting in which failure to provide irrigation during these periods results in several impacts such as flower shedding, lack of fertilization, reduced fruit number, size, fruit splitting, blossom end rot (BER) and poor seed viability.
Drought involves a complex mechanism as a result of which the breeding and development of drought tolerant tomato hybrids and cultivars under water deficit conditions is still in the initial phase. To breed drought tolerant tomato hybrids with high yield potential, several drought tolerant wild species viz., $S$. cheesmanii, $S$. chilense, $S$. pennellii, $S$. pimpenelifolium, $S$. lycopersicum var. cerasiforme (Foolad, 2003) can be introduced and hybridized into the elite varieties or accessions. Drought involves a complex mechanism which explains the limited work and slow progress in breeding tomato for drought conditions. In order to bridge this gap, thus, an attempt is being made to screen tomato genotypes for drought tolerance with full yield potential and better quality under high water deficit regime on the basis of morphological, physiological and biochemical traits.

\section{Materials and Methods}

The present study was undertaken to assess the morphological and physiological parameters for drought tolerance in tomato genotypes under pot culture conditions in the Department of Vegetable Crops, Tamil Nadu Agricultural University, Coimbatore, Tamil Nadu during 2014-2015. The experiment was conducted with 32 genotypes (Table 1) using two treatments viz., 100 per cent field capacity (FC) and 50 per cent field capacity (FC) with three replications which was laid out in factorial completely randomized block design (FCRD). The seeds of selected genotypes were sown in protrays filled with cocopeat and vermicompost which were kept in the nursery. Pots of uniform size $(50 \times 30$ $\mathrm{m}^{2}$ ) were filled with potting mixture (red earth, sand and FYM in the ratio of $1: 1: 1$ ) and saturated with water and the field capacity of the soil was recorded. The twenty-five days old seedlings were transplanted and one plant was maintained in each pot. The treatment 
100 per cent FC as control and 50 per cent FC as drought stress were imposed to the seedlings at 15 days after transplanting and is given by weighing and watering each pot at regular intervals. The observations viz., plant height, root fresh weight, root dry weight, number of flowers drop, number of fruits per plant and fruit yield per plant were recorded at 60 days after sowing by selecting randomly five representative samples from each replication and are furnished in tables 2 and 3.

The specific leaf weight was determined by a procedure described by Pearce et al., (1969). The physiologically active leaves of each plant were collected and the area of each leaf was measured using Biovis PSM - 12000 Leaf area meter Analysis System. The specific leaf weight is calculated by the ratio of leaf dry weight to the leaf area which is expressed as $\mathrm{g} / \mathrm{cm}^{2}$.Chlorophyll stability index (CSI) was estimated according to the protocol of Koleyoreas (1958) and the leaf relative water content (RWC) was calculated using the method described by Barrs and Weatherly (1962). Proline was estimated following the procedure of Bates et al., (1973). The data on various characters of tomato were subjected to statistical analysis.

\section{Results and Discussion}

The per se performance of thirty tomato genotypes under control and stressed conditions with respect to growth, yield, physiological and biochemical parameters is presented in tables 2, 3 and 4. The present study revealed that plants imposed with 100 per cent FC recorded higher average plant height than 50 per cent FC plants. Among the genotypes, LE-114 showed significantly taller plants $(96.43 \mathrm{~cm})$ followed by $\mathrm{LE}-57$ $(91.23 \mathrm{~cm})$ and Arka Ashish $(87.57 \mathrm{~cm})$ under controlled conditions, whereas LE-114 $(86.43 \mathrm{~cm})$, LE-57 $(91.23 \mathrm{~cm})$ and IIVR-L $(80.93 \mathrm{~cm})$ under treated conditions (Table 2).
In both the treatments, LE-114 showed less reduction of plant height hence, it can be considered as tolerant. Drought induced a significant reduction in plant height as compared to control. The reduction in plant height was associated with a decline in the cell elongation or enlargement and more leaf senescence under water stress, which might be due to turgor loss under drought (Manivannan et al., 2007). The growth reduction under water-stress conditions has been well characterized in tomato (Garcia et $a l$. , 2007). Therefore, plant height can be considered as an important trait for determining drought tolerance under water stress condition since increased plant height would allow greater biomass production and yield potential in crops.

The genotype LE-114 showed the maximum root fresh weight $(51.10 \mathrm{~g})$ followed by LE-57 (49.90g), LE-118 (48.64g) for control and; LE-114 (53.12g), LE-57 (52.21g) and LE-118 $(50.33 \mathrm{~g})$ for 50 per cent FC. The root dry weight at 100 per cent FC showed maximum in genotype LE-114 (13.39g) followed by LE57 (11.48g) and LE-118 (10.71g) whereas, under 50 per cent FC, the accession IIVR-L recorded the maximum root dry weight of (11.38g) followed by EC-177371 (11.30g) and EC-177343 (11.25g) (Table 2). The increment of root fresh and dry weight under water deficit condition might be due to the increased osmotic pressure by the accumulation of compatible osmolyte such as proline which keeps the leaf water potential lower than that of soil water potential which ultimately, leads to the induction of root growth for search of water. The present study is in accordance with the earlier findings of Djibril et al., (2005). Therefore, an extensive root system is advantageous to support plant growth during the early crop growth stage and extract water from shallow soil layers that is otherwise easily lost by evaporation. 
The number of flowers drop under 100 per cent FC was minimum in EC-177325 (7) followed by LE-118 (7.67) and LE-114 (10) and under stressed condition, minimum flower drop was attained in LE-118 (6.33), BRML (7.67) and LE-114 (7.33) (Table 3). The maintenance of photosynthesis and efficient translocation of photosynthates to the reproductive parts under drought is the main reason for lower flower abscission in the tolerant genotypes. The reduction in photosynthesis during stress may decrease the availability of assimilates to the developing floral organs and leads to the abscission of flowers and flower buds in susceptible cultivars. According to Srivastava et al., (2012), drought-induced high temperature also caused bud and flower drop up to 42.56 per cent in tomato.

Data on fruit number showed that irrespective of the genotypes, the fruit number decreased under drought compared to control. Comparing the treatments, plants imposed with 100 per cent FC recorded higher number of fruits per plant (79.67) than plants received 50 per cent FC (54). Among the genotypes, LE 57 (79.67) recorded significantly higher number of fruits followed by IIVR-L (68.33) under control. At 50 per cent FC, LE 57 (54) recorded significantly higher number of fruits followed by LE 114 (50.67) and IIVR-L (44.67), while the lowest number of fruits per plant was recorded by EC-608395 (8.67) and EC-170047 (9.00) (Table 3). The decreased production of more number of fruits per plant under water deficit conditions results from the increased bud and flower drop as compared to controlled plants which might be due to the reduced availability of photo assimilates as discussed above.

There is a decrease in fruit yield as water stress increases. The genotype LE-57 showed the maximum fruit yield $(794.70 \mathrm{~g}$ ) followed by LE-118 (751.92g), LE-27(691.06 g) in control and in IIVR-L (563.05g), LE-57 (533.86g) and LE-27 (468.96g) for 50 per cent FC. The drought tolerant genotypes of tomato out-yielded those of susceptible ones.

The reduction in fruit yield and other related parameters may probably due to the reduced water content in the plant which leads to the disruption of leaf gas exchange properties which further limits the source size, activity (photosynthesis) and photo assimilates partitioning to fruits (sink sixe and activity). Furthermore, the reduction in crop yields depend on both the intensity and duration of stress period, species, cultivar of the same species as reported by Ashraf (2010). Therefore, it can be clearly said that water deficit as a result of soil drying caused a major effect on yield and yield components even in genotypes that are drought tolerant.

\section{Specific leaf area (SLA)}

The specific leaf area (SLA) decreased with the increased water stress condition. The genotypes EC-608395 (47.79 $\left.\mathrm{cm}^{2} / \mathrm{g}\right)$, EC$177393\left(41.62 \mathrm{~cm}^{2} / \mathrm{g}\right)$ and EC-177343 (35.90 $\left.\mathrm{cm}^{2} / \mathrm{g}\right)$ recorded maximum specific leaf area among the genotypes whereas, IIVR-L (9.83 $\left.\mathrm{cm}^{2} / \mathrm{g}\right)$, Arka Meghali (11.28 $\left.\mathrm{cm}^{2} / \mathrm{g}\right)$, EC$170089\left(15.21 \mathrm{~cm}^{2} / \mathrm{g}\right)$ and EC-168282 (15.50 $\mathrm{cm}^{2} / \mathrm{g}$ ) showed the minimum specific leaf area (Table 4).

The highest SLA results from longer leaf lengths and wider widths. Crop species with more rapidly elongating leaves showed faster increase in leaf expansion rate, leaf width and leaf area and more biomass allocation to leaf sheaths and less to roots (Bultynck et al.,2004). The alterations in leaf structural parameters are due to reductions in cell expansion and intercellular spacing which in turn produced a compact leaf, with small leaf area and greater leaf thickness. 
Table.1 The genotypes used in the study

\begin{tabular}{|c|c|c|c|c|c|}
\hline SI. No. & Accession No. & Source & Sl. No. & Accession No. & Source \\
\hline 1. & $E C-167860$ & \multirow{16}{*}{ NBPGR, Hyderabad } & 17. & Arka Vikas & \multirow{5}{*}{ IIHR, Bangalore } \\
\hline 2. & $E C-168281$ & & 18. & Arka Ashish & \\
\hline 3. & EC - 168282 & & 19. & IIHR - 709 & \\
\hline 4. & $E C-168283$ & & 20. & IIHR - 2388 & \\
\hline 5. & $E C-168290$ & & 21. & EC - 608395 & \\
\hline 6. & EC - 169966 & & 22. & $\mathrm{EC}-608406$ & \multirow{11}{*}{ TNAU, Coimbatore } \\
\hline 7. & $\mathrm{EC}-170047$ & & 23. & EC - 608456 & \\
\hline 8. & $\mathrm{EC}-170089$ & & 24. & Vybhav & \\
\hline 9. & $E C-175957$ & & 25. & BRML & \\
\hline 10. & $\mathrm{EC}-177325$ & & 26. & IIVR $-\mathrm{L}$ & \\
\hline 11. & $\mathrm{EC}-177343$ & & 27. & $\mathrm{LE}-27$ & \\
\hline 12. & $\mathrm{EC}-177360$ & & 28. & $\mathrm{LE}-57$ & \\
\hline 13. & EC - 177371 & & 29. & $\mathrm{LE}-114$ & \\
\hline 14. & $\mathrm{EC}-177393$ & & 30. & LE - 118 & \\
\hline 15. & EC - 177824 & & 31. & $\mathrm{LE}-812$ & \\
\hline 16. & Arka Meghali & & 32. & PKM-1 & \\
\hline
\end{tabular}


Table.2 Effect of water deficit on plant height, root fresh weight and root dry weight of tomato genotypes

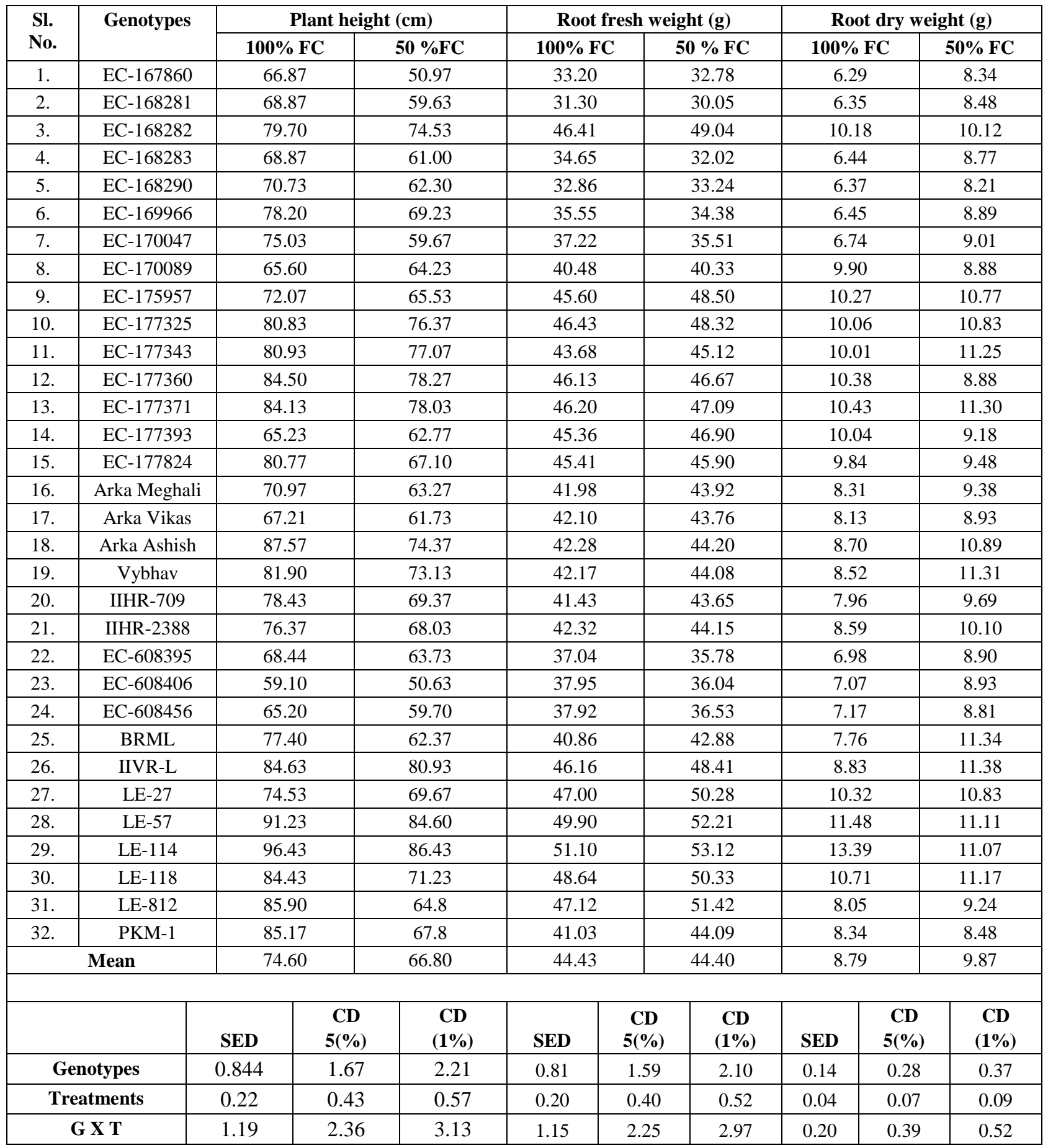


Table.3 Effect of water deficit on no. of flowers/plant, no. of fruits/plant and fruit yield/plant of tomato genotypes

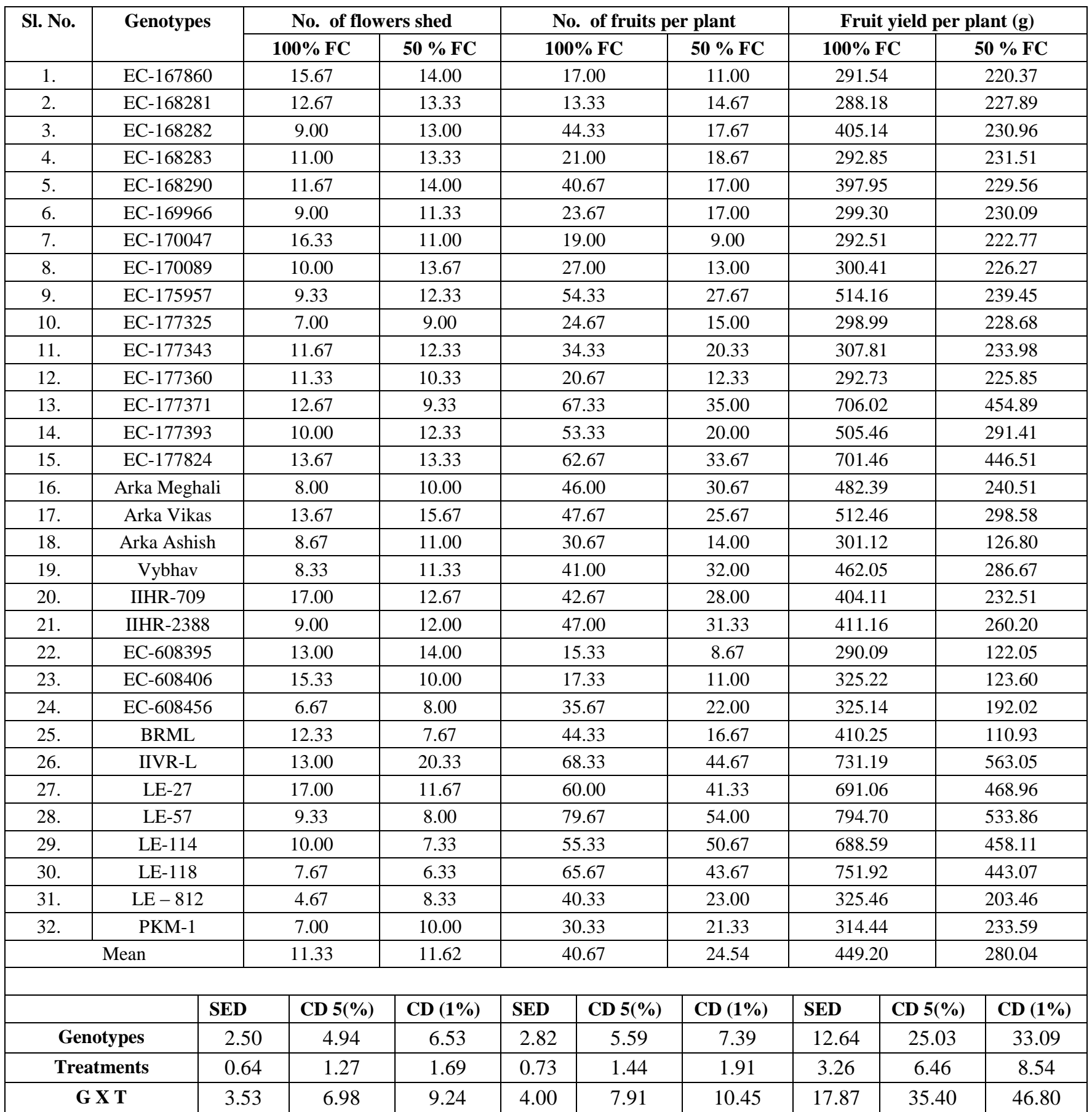


Table.4 Effect of water deficit on SLA, CSI, RWC and proline content of tomato genotypes

\begin{tabular}{|c|c|c|c|c|c|c|c|c|c|c|c|c|c|c|}
\hline \multirow[t]{2}{*}{$\begin{array}{l}\text { Sl. } \\
\text { No. }\end{array}$} & \multirow{2}{*}{\multicolumn{2}{|c|}{ Genotypes }} & \multicolumn{2}{|c|}{$\begin{array}{c}\text { Specific leaf area } \\
\left(\mathrm{cm}^{2} / \mathrm{g}\right)\end{array}$} & \multicolumn{4}{|c|}{$\begin{array}{l}\text { Chlorophyll stability } \\
\text { index }(\%)\end{array}$} & \multicolumn{3}{|c|}{$\begin{array}{c}\text { Relative water content } \\
(\%)\end{array}$} & \multicolumn{3}{|c|}{ Proline $(\mu \mathrm{g} / \mathrm{g})$} \\
\hline & & & $100 \% \mathrm{FC}$ & $50 \%$ FC & \multicolumn{2}{|c|}{$100 \%$ FC } & \multicolumn{2}{|c|}{$50 \%$ FC } & \multicolumn{2}{|c|}{$100 \%$ FC } & $\mathbf{5 0} \%$ FC & \multicolumn{2}{|c|}{$100 \% \mathrm{FC}$} & $50 \%$ FC \\
\hline 1. & \multicolumn{2}{|c|}{ EC-167860 } & 50.18 & 32.48 & \multicolumn{2}{|c|}{63.09} & & 59.51 & \multicolumn{2}{|c|}{55.40} & 48.83 & \multicolumn{2}{|c|}{203.11} & 216.65 \\
\hline 2. & \multicolumn{2}{|c|}{ EC-168281 } & 33.36 & 28.88 & \multicolumn{2}{|c|}{71.94} & & 78.44 & \multicolumn{2}{|c|}{58.15} & 52.66 & \multicolumn{2}{|c|}{173.51} & 259.32 \\
\hline 3. & \multicolumn{2}{|c|}{ EC-168282 } & 47.33 & 15.63 & 92.6 & & & 85.02 & \multicolumn{2}{|c|}{59.77} & 50.44 & \multicolumn{2}{|c|}{342.74} & 349.87 \\
\hline 4. & EC-16 & 283 & 33.46 & 19.43 & 69.6 & & & 58.78 & 49. & & 46.31 & & & 125.86 \\
\hline 5. & EC-16 & 290 & 34.03 & 30.25 & 68.2 & & & 58.58 & 49. & & 41.41 & & & 323.80 \\
\hline 6. & EC-16 & 966 & 35.73 & 34.92 & 73.7 & & & 68.21 & 54. & & 40.93 & & & 203.76 \\
\hline 7. & EC-17 & 047 & 44.25 & 33.19 & 70.0 & & & 67.47 & 51. & & 39.61 & & & 310.86 \\
\hline 8. & EC-17 & 089 & 32.22 & 14.99 & 71.3 & & & 59.61 & 57. & & 50.46 & & & 289.82 \\
\hline 9. & EC-17 & 957 & 35.25 & 22.64 & 81.6 & & & 66.36 & 53. & & 49.21 & & & 253.10 \\
\hline 10. & EC-17 & 325 & 22.99 & 18.73 & 89.1 & & & 86.24 & 70. & & 68.02 & & & 371.32 \\
\hline 11. & EC-17 & 343 & 34.88 & 36.55 & 70.1 & & & 64.02 & 66. & & 42.34 & & & 251.34 \\
\hline 12. & EC-17 & 360 & 24.70 & 23.71 & 65.4 & & & 61.16 & 57. & & 43.74 & & & 248.17 \\
\hline 13. & EC-17 & 371 & 38.18 & 18.36 & 91.4 & & & 83.66 & 69. & & 64.19 & & & 365.53 \\
\hline 14. & EC-17 & 393 & 64.74 & 40.63 & 79.1 & & & 73.35 & 49. & & 47.88 & & & 272.68 \\
\hline 15. & EC-17 & 824 & 32.34 & 28.74 & 80.3 & & & 78.02 & 59. & & 48.40 & & & 273.09 \\
\hline 16. & Arka $\mathrm{N}$ & eghali & 36.88 & 46.16 & 75.3 & & & 73.02 & 73. & & 59.93 & & & 340.81 \\
\hline 17. & Arka & kas & 38.85 & 33.30 & 73.4 & & & 69.82 & 55. & & 41.39 & & & 312.20 \\
\hline 18. & Arka $A$ & shish & 27.37 & 24.05 & 68.6 & & & 63.30 & 46. & & 43.20 & & & 319.08 \\
\hline 19. & Vybha & & 35.09 & 10.24 & 74.9 & & & 71.29 & 52. & & 46.08 & & & 360.40 \\
\hline 20. & IIHR- & & 27.76 & 21.27 & 90.5 & & & 85.16 & 61. & & 59.91 & & & 384.85 \\
\hline 21. & IIHR-2 & 388 & 31.45 & 28.94 & 75.4 & & & 67.91 & 45 & & 39.80 & & & 311.90 \\
\hline 22. & EC-60 & 395 & 27.13 & 28.06 & 55.2 & & & 35.51 & 47. & & 46.79 & & & 286.84 \\
\hline 23. & EC-60 & 406 & 34.73 & 25.16 & 60.1 & & & 59.13 & 57. & & 45.44 & & & 281.49 \\
\hline 24. & EC-60 & 456 & 39.49 & 25.28 & 60.3 & & & 55.21 & 40. & & 37.04 & & & 294.69 \\
\hline 25. & BRML & & 37.35 & 29.66 & 81.3 & & & 73.49 & 48. & & 48.89 & & & 350.86 \\
\hline 26. & IIVR-I & & 148.23 & 7.49 & 93.7 & & & 88.43 & 70. & & 66.08 & & & 410.20 \\
\hline 27. & LE-27 & & 27.13 & 27.85 & 89.6 & & & 78.46 & 64. & & 59.43 & & & 407.31 \\
\hline 28. & LE-57 & & 48.64 & 19.36 & 86.5 & & & 81.59 & 71. & & 67.44 & & & 405.83 \\
\hline 29. & LE-11 & & 25.97 & 19.54 & 91.7 & & & 87.35 & 67. & & 65.69 & & & 420.20 \\
\hline 30. & LE-11 & & 27.42 & 21.24 & 85.4 & & & 75.31 & 47. & & 45.90 & & & 322.60 \\
\hline 31. & LE-81 & & 34.06 & 22.92 & 51.1 & & & 52.80 & 44. & & 45.88 & & & 219.78 \\
\hline 32. & PKM- & & 50.18 & 32.48 & 46.2 & & & 29.96 & 39. & & 23.04 & & & 265.64 \\
\hline & Mean & & 40.66 & 26.64 & 76.6 & & & 70.45 & 57. & & 50.25 & & & 310.81 \\
\hline & & SED & CD 5(\%) & CD (1\%) & SED & CD & $5(\%)$ & CD (1\%) & SED & CD 5 $(\%)$ & CD (1\%) & SED & CD (1\%) & $\begin{array}{c}\text { CD } \\
(1 \%) \\
\end{array}$ \\
\hline Gen & types & 9.53 & 18.68 & 24.59 & 1.04 & & 06 & 2.72 & 0.71 & 1.41 & 1.86 & 1.26 & 2.50 & 3.31 \\
\hline Trea & ments & 2.38 & 4.67 & 6.15 & 0.27 & & 53 & 0.70 & 0.18 & 0.36 & 0.48 & 0.33 & 0.65 & 0.86 \\
\hline & $\mathbf{X ~ T}$ & 13.48 & 26.42 & 34.77 & 1.47 & & 91 & 3.85 & 1.00 & 2.00 & 2.63 & 1.78 & 3.54 & 4.68 \\
\hline
\end{tabular}

According to Calcagno et al., (2011), in a C3 crop like tomato an increase in leaf thickness leads to a thicker palisade parenchyma, which could contain larger numbers of $\mathrm{CO}_{2}$ fixation sites, while a thicker spongy parenchyma could result in easier $\mathrm{CO}_{2}$ diffusion to these sites. Then the leaf structure changed to a more compact and thicker one but with a smaller area. 
This alteration could be counted as a change in the leaf structure during drought stress period and is maintained at rehydration in order to improve tolerance and increase productivity during recovery events. This trait alone is not enough to determine the drought tolerance of tomato genotypes. There have been many reports on reduced specific leaf area under drought conditions (Guerfel et al., 2009).

\section{Chlorophyll stability index (CSI)}

Tomato genotypes responded variably for CSI under stressed conditions and there is a reduction in chlorophyll stability index (CSI) under water stress situation. The genotypes IIVR-L (88.43\%), LE-114 (87.35\%), EC177325 (86.24\%), IIHR-709 (85.16\%) and EC$168282(85.02 \%)$ recorded high CSI while EC608395 (35.51\%) and EC-608456 (55.21\%) recorded lower CSI under stressed condition (Table 4.).The genotypes with increased CSI under drought stress condition can be selected as drought tolerant genotypes. The reasonable explanation for reduction of leaf chlorophyll, as well as the increase of proline content may probably due to the ability of reactive oxygen species to cause photo oxidative damages in organic molecules (Smirnoff, 1995). Decreased chlorophyll under water stress generally occurs due to damage of chloroplasts caused by oxidative bursts or due to changed ratios of lipid protein complexes or elevated chlorophyllase activity which degrades the chlorophyll and damages the light harvesting machinery (Kaya et al., 2006). In contrast, plants showing increased chlorophyll values are considered to be drought tolerant. Decreased CSI with increased water stress has been reported by George et al., (2015) in tomato.

\section{Relative water content (RWC)}

Results showed the decreased RWC under water deficit condition. Among the genotypes, EC-177325 (68.02\%), LE-57 (67.44\%), IIVR-L $(66.08 \%)$ and LE-114 (65.69\%) recorded the highest RWC, while EC-608456 (37.04\%), EC170047 (39.61\%) and IIHR-2388 (39.80\%) revealed the lowest RWC under water deficit condition (Table 4). Water deficit exert a negative effect on relative water content, thus the ability of the plant to survive severe water deficits depends on its ability to restrict water loss through the leaf epidermis after the stomata have attained minimum aperture. It should be kept in mind that the more water is absorbed during imbibitions, the greater the turgid mass and the smaller the corresponding value of relative water content (Sibomana et al., 2013). These genotypes having higher RWC exhibited better drought tolerance capacity implying their more favourable internal water relations which was similar to the results reported by Sivakumar et al., (2014) in tomato.

\section{Proline content under drought}

Proline content was found to increase with increasing water stress. Tomato genotypes were significantly different for proline contents. The results revealed that among all the genotypes, LE 114 recorded higher proline content (420.20 $\mu \mathrm{g} / \mathrm{g})$ followed by IIVR-L $(410.20 \mu \mathrm{g} / \mathrm{g})$, LE 27 $(407.31 \mu \mathrm{g} / \mathrm{g})$ and LE $57(405.83 \mu \mathrm{g} / \mathrm{g})$, while comparatively lower proline content were observed in EC-168283 (125.86 $\mu \mathrm{g} / \mathrm{g})$ and EC$169966(203.76 \mu \mathrm{g} / \mathrm{g})$ at 50 per cent FC (Table 4). Accumulation of proline in the plant system lowers the water potential of plant than that of soil, which helps the root to absorb water from soil. Numerous research have been reported for the accumulation of osmolytes in plants under drought which is induced by dehydration or hyper osmotic conditions. Hence, proline content can be used as a trait for selection in breeding drought tolerant genotypes as reported by several workers (Giannakoula and Ilias, 2013.). It can be concluded that proline is one of the reliable indicator for determining the drought stress tolerant genotypes.

It is concluded from the present study, all the investigated traits showed large variation in optimal and stress conditions. Morphological parameters revealed diverse behaviour among different tomato genotypes and distinct characters were observed depending on the 
treatments. Among all thirty genotypes, accessions IIVR-L, LE-27, LE-57, LE-114 and LE-118 revealed the tolerance capacity against drought since they performed better under water deficit conditions for maximum plant height, root fresh and dry weight, number of fruits per plant, fruit yield per plant, chlorophyll stability index, relative water content and proline content but a minimum number of flower shed. The significant differences which were observed among the genotypes in root dry weight, number of flower drop and number of fruits per plant also indicated wide diversity among them that enabled the screening of drought-tolerant genotypes. These results showed that all the genotypes exhibited a wide response to water stress for various morphological and physiological traits. However, the genotypes IIVR-L, LE-27, LE-57, LE-114 and LE-118 can be used for breeding drought-tolerant genotypes with higher yield and also as sources of drought responsive genes for crop improvement programme in tomato.

\section{Acknowledgement}

I thank the National Bureau of Plant Genetic Resources (NBPGR), New Delhi, Indian Institute of Horticulture (IIHR), Bangalore and Indian Institute of Vegetable Research (IIVR), Varanasi for providing me with the seed materials for my research programme and also the University Grants Commission for providing a fellowship during the period of research.

\section{References}

Agarwal, S. and Rao, A.V. 2000. Tomato lycopene and its role in human health and chronic diseases. Canad. Med. Association J., 163(6): 739-744.

Anang, B.T., Z.A. Zulkarnain, and Yusif, S. 2013. Production constraints and measures to enhance the competitiveness of the tomato industry in Wenchi Municipal District of Ghana. Amer. J. Expt. Agri, 3(4): 824-838.

Ashraf, M. 2010. Inducing drought tolerance in plants: Recent advances. Biotechnol. Adv., 28: 169- 183.

Barrs, H.D. and Weatherley, P.E. 1962. A reexamination of relative turgidity for estimating water deficits in leaves. Austr. J. Biol. Sci., 15: 413 - 428.

Bates, L.S., P.P. Waldren and Teare, I.D. 1973. Rapid determination of proline for water stress studies. Plant and Soil, 39: 205207.

Bultynck, L., M.W.T. Steege, M. Schortemeyer, P. Poot and Lambers, H. 2004. From individual leaf elongation to whole shoot leaf area expansion: a comparison of three Aegilops and two Triticum species. Ann. Bot., 94 (1): 99-108.

Calcagno, A.M., Rivas M. and Castrillo, M. 2011. Structural, physiological and metabolic integrated responses of two tomato (Solanum lycopersicum L.) cultivars during leaf rehydration. Austr. J. Crop Sci., 5(6): 695 - 701.

Chatterjee, A. and Solankey, S.S. 2015. Functional physiology in drought tolerance of vegetable crops-an approach to mitigate climate change impact. Climate Dynamics Hort. Sci., (1): 150-171.

Djibril, S., O.K. Mohamed, D. Diaga, D. Diegane, B.F. Abaye, S. Maurice and Alain, B. 2005. Growth and development of date palm (Phoenix dactylifera L.) seedlings under drought and salinity stresses. Afr. J. Biotechnol., 4: 968-972.

Foolad, M.R., L.P. Zhang, and Subbiah, P. 2003. Genetics of drought tolerance during seed germination in tomato: inheritance and QTL mapping. Genome, 46: 536-545.

Garcia, A.L., L. Marcelis, F. Garcia-Sanchez, N. Nicolas and Martinez, V. 2007. Moderate water stress affects tomato leaf water relations in dependence on the nitrogen supply. Biol. Plant., 51(4): 707712.

George, S., N.M. Minhas, S.A. Jatoi, S.U. Siddiqui and Ghafoor, A. 2015. Impact of polyethylene glycol on proline and membrane stability index for water stress 
regime in tomato (Solanum lycopersicum). Pak. J. Bot., 47 (3): 835 844.

Giannakoula, A.E. and Ilias, I. F. 2013. The effect of water stress and salinity on growth and physiology of tomato (Lycopersicon esculentum Mill.). Arch. Biol. Sci., 65 (2): 611-620.

Guerfel, M.O. Baccouri, D. Boujnah, W. Chaibi and Zarrouk, M. 2009. Impacts of water stress gas exchange, water relations, chlorophyll content and leaf structure in the two main Tunisian olive (Olea europaea L.) cultivars. Sci HorticAmsterdam, 119: 257-263.

Kaya, C., L. Tuna and Higgs, D. 2006. Effect of silicon on plant growth and mineral nutrition of maize grown under water stress conditions. J. Plant Nutri., 29: 1469-1480

Koleyoreas, A.S. 1958. A new method of determining drought resistance. Plant Physiol., 33: 232-233.

Leonardi, C., S. Guichard and Bertin, N. 2000. High vapour pressure deficit influences growth, transpiration and quality of tomato fruits. Scientia Horticulturae, 84(3): 285-296.

Manivannan, P., C.A. Jaleel, B. Sankar, A. Kishorekumar, R. Somasundaram, G. M. A. Lakshmanan and Panneerselvam, R. 2007. Growth, biochemical modifications and proline metabolism in Helianthus annuus L. as induced by drought stress. Colloids Surf. B. Biointerf., 59: 141-149.

Mir, R.R., M. Zaman-Allah, N. Sreenivasulu, R. Trethowan and Varshney, R.K. 2012. Integrated genomics, physiology and breeding approaches for improving drought tolerance in crops. Theor. Appl. Genet., 125: 625-645.

Mishra, U.A., Rai, R., Kumar, M., Singh and Pandey, H.P. 2016. Gene expression analysis of Solanum lycopersicum and Solanum habrochaites under drought conditions. Genomics Data, doi: 10.1016/j.gdata.2016.04.001.

Pearce, R.B., G.E. Carlson, D.K. Barnes, R.H. Hart, and Hanson, C.H. 1969. Specific leaf weight and photosynthesis in alfalfa. Crop Sci., 9: 423-426.

Schachtman, D.P. and Goodger, J.Q.D. 2008. Chemical root to shoot signaling under drought. Trends Plant Sci., 13: 281-287

Sibomana, I.C. J.N. Aguyoh and Opiyo, A.M. Water stress affects growth and yield of container grown tomato (Lycopersicon esculentum Mill,) plants. Global J. Biosci Biotechnol., 2(4): 461 - 466.

Sivakumar, R., D. Durga Devi, C.N. Chandrasekar, R. Santhi and Vijayakumar, R.M. 2014. Impact of drought on gas exchange and physiological parameters and yield in contrasting genotypes of tomato (Solanum lycopersicum). Indian J. Plant Physiol., 19(1): 1-7.

Smirnoff, N. 1995. Antioxidant systems and plant response to the environment. In V. Smirnoff (Ed.), Environment and plant metabolism: Flexibility and acclimation. Oxford: BIOS Scientific Publishers.

Srivastava, K., Kumar, S., Prakash, P. and Vaishampayan, A. 2012. Screening of tomato genotypes for reproductive characters under high temperature stress conditions. Sabrao J. Breed. Genet., 44(2): 263-276.

\section{How to cite this article:}

Salvadora Buhroy, T. Arumugam, P. Irene Vethamoni, N. Manivannan and P. Jeyakumar. 2017. Effectiveness of Drought Tolerance Indices to Identify Tolerant Genotypes with High Yielding Potential in Tomato (Solanum lycopersicum L.). Int.J.Curr.Microbiol.App.Sci. 6(4): 2093-2103. doi: https://doi.org/10.20546/ijcmas.2017.604.247 